\title{
HUBUNGAN DUKUNGAN KELUARGA DENGAN PERUBAHAN KONSEP DIRI PADA PASIEN PASCA STROKE DI POLIKLINIK SYARAF RUMAH SAKIT STROKE NASIONAL BUKITTINGGI TAHUN 2016
}

\author{
Melti Suriya ${ }^{1}$ \\ ${ }^{1}$ STIKes Alifah Padang, Jln Khatib Sulaiman No. 52 B, Padang, 25000, Indonesia \\ Email: melti_s85@yahoo.com
}

\begin{abstract}
Abstrak
Menurut World Health Organization (WHO) tahun 2014 menunjukkan bahwa 63\% penyebab kematian di seluruh dunia disebabkan oleh penyakit tidak menular yaitu stroke atau setara dengan kematian 36 juta jiwa per tahun. Pasien pasca stroke yang memandang dirinya secara negatif tidak mampu memandang sisi positif dari cacat yang dideritanya. Pasien tersebut memandang dirinya sebagai indivindu yang cacat, tidak mampu memenuhi tuntutan moral, penuh kekurangan. Tujuan penelitian ini untuk mengetahui hubungan dukungan keluarga dengan perubahan konsep diri pada pasien pasca stroke di RS. Stroke Nasional Bukittinggi tahun 2016. Jenis penelitian analitik dengan desain cross sectional. Populasi dalam penelitian ini adalah seluruh pasien stroke haemoragik yang datang berkunjung pada bulan Februari - Maret 2016 sebanyak 366 orang dengan sampel 46 orang. Teknik pengambilan sampel accidental sampling. Penelitian dilakukan pada tanggal 06 - 17 Juni 2016. Data dianalisa secara univariat menggunakan table distribusi frekuensi dan bivariat menggunakan ujia statistik Chi-Square dengan tingkat kepercayaan $95 \% \alpha=0,05$. Hasil penelitian menunjukan bahwa kurang dari separuh 43,5\% memiliki konsep diri negatif. Kurang dari separuh 41,3\% memiliki keluarga tidak mendukung. Ada hubungan dukungan keluarga dengan konsep diri $(p$ value $=0,010)$. Kesimpulan penelitian ini adalah ada hubungan dukungan keluarga dengan konsep diri pasien stroke. Diharapkan tenaga kesehatan di RS. Stroke Nasional Bukittinggi agar dapat memberikan informasi kepada pasien pasca stroke agar dapat memberikan bimbingan konseling tentang pentingnya dukungan keluarga terhadap konsep diri pada pasien pasca stroke sehingga pasien dapat percaya diri dengan keadaanya sekarang.
\end{abstract}

Kata kunci: Stroke, Dukungan keluarga dan konsep diri

\begin{abstract}
World Health Organization (WHO) in 2014 shows that 63\% of death case world widely wass caused by non-communicable diseases, namely stroke or it is equivalent to 36 million deaths a year. Poststroke patient who see themselves negatively not able to see the positive side of the defect in misery. The patient sees himself as an individual with a disability, unable to meet the demands of the moral, full of flawar. The purpose of this study is to determine the relationship between family support and self-concept changes in post-stroke patients in National Stroke Hospital of Bukittinggi 2016. The type of analytical research was cross sectional design. The population of this research was the total number of stroke haemoragic who visited in February - March 2016 there were 366 people with 46 of the sampling. The sampling technique Accidental sampling. This research was held on June 06- 17 june 2016. These Data were analyzed by using univariate which used frequency distribution table and bivariate which use statistical test Chi-Square with $\alpha 95 \%$ confidence level $\alpha=0.05$. The results of the research showed that less than (43.5\%) respondents have negative self-concept. More than $(41.3 \%)$ respondents have unsupported family. There was a relationship between family support and self-concept ( $\mathrm{p}$ value $=0,010$ ). In conclusion family support can affect self-concept in stroke patients. Health worker aslo can be expect in National Stroke Hospital of Bukittinggi can give the information to post stroke patients family to
\end{abstract}


regard the post stroke patien and can give counseling guidance about the importance of family support for build the self-concept of post-stroke patient to make then feel more confident with their condition.

\section{Keywords: Stroke, Family Support and Self-Concept \\ I. PENDAHULUAN}

Stroke adalah gangguan fungsional yang terjadi secara mendadak disebabkan karena kurangnya atau terputusnya aliran darah yang mengalir ke otak akibat adan ya gumpalan darah, endapan plak, atau karena pecahnya pembuluh darah akibat tekanan darah yang tinggi secara tiba-tiba ke otak. Hal ini yang mengakibatkan sel-sel otak mengalami kekurangan oksigen serta energi dan menyebabkan kerusakan otak permanen yang berakibat kecacatan sampai dengan kematian dini (Kemenkes RI, 2013).

Menurut World Health Organization (WHO) tahun 2014 menunjukkan bahwa 63\% penyebab kematian di seluruh dunia disebabkan oleh penyakit tidak menular yaitu stroke atau setara dengan kematian 36 juta jiwa per tahun. Prevalensi stroke di Indonesia 12,1 per 1.000 penduduk. Penderita stroke terbanyak Nanggroe Aceh Darussalam 16,6 per 1000 penduduk dan yang terendah adalah Papua 3,8 per 1000 penduduk. Sedangkan di Sumatera Barat menempati urutan keenam penyakit stroke sebanyak 10,6 per 1000 penduduk. Menurut data Badan Pusat Statistik Kota Padang tahun 2014, stroke adalah penyebab kematian kelima di Kota Padang dengan persentase $8 \%$ setelah penyakit ketuaan/lansia, DM, Hipertensi, Jantung (Riskesdas, 2013).

Berdasarkan hasil Riskesdas tahun 2013, prevalensi penyakit stroke di Indonesia meningkat seiring bertambahnya umur. Kasus stroke tertinggi yang terdiagnosis tenaga kesehatan adalah usia 75 tahun keatas $(43,1 \%)$ dan terendah pada kelompok usia 15-24 tahun yaitu sebesar $0,2 \%$. Prevalensi stroke berdasarkan jenis kelamin lebih banyak laki-laki $(7,1 \%)$ dibandingkan dengan perempuan $(6,8 \%)$.

Kondisi yang dapat terjadi pada pasien stroke beragam, seperti kelumpuhan anggota gerak, bibir tidak simetris, bicara pelo atau apasia (tidak dapat berbicara), nyeri kepala, penurun kesadaran, gangguan rasa, kelumpuhan bahkan sampai dengan kematian. Kehilangan fungsi tubuh akibat penyakit stroke mengakibatkan produktifitas pasien stroke terhalang dan berpengaruh pada status fungsional pasien stroke (Junaidi, 2011).

Dampak dari penyakit stroke penderita dapat mengalami berbagai masalah diantaranya gangguan kesadaran, gangguan mobilitas fisik, gangguan menelan dan gangguan perawatan diri. Secara psikologis, penderita pasca stroke memiliki perubahan dan keterbatasan dalam bergerak, berkomunikasi, dan berfikir yang nantinya akan sangat mengganggu fungsi peran penderita. Dengan kondisi pasca stroke yang demikian, penderita akan merasa dirinya cacat dan kecacatan ini menyebabkan self-esteem terganggu (Syaiful, 2009).

Seringkali stroke diikuti oleh gangguan psikologis termasuk gangguan konsep diri yang terjadi karena dua faktor. Faktor yang pertama adalah pada penderita stroke terjadi sumbatan atau pecahnya pembuluh darah di otak yang menyebabkan jalur komunikasi ke daerah otak tersebut menjadi terhambat dan gangguan fungsi perasaan sehingga gangguan suasana perasaan dan tingkah laku.

Selain itu, gangguan psikologis pada pasien stroke juga disebabkan karena adanya ketidakmampuan pasien dalam melakukan sesuatu yang biasanya dikerjakan sebelum terkena stroke (Keliat, 2008).

Menurut teori Maslow konsep diri merupakan salah satu kebutuhan urutan no. 4 yaitu kebutuhan esteem dimana ketika tiga kelas pertama kebutuhan dipenuhi. Ketika kebutuhan terpenuhi, orang merasa percaya diri dan berharga sebagai orang di dunia. Ketika kebutuhan frustrasi, orang merasa rendah, lemah, tak berdaya dan tidak berharga (Hariyanto, 2010).

Konsep diri merupakan semua pikiran, keyakinan dan kepercayaan yang merupakan pengetahuan individu tentang dirinya mempengaruhi hubungannya dengan orang lain. Komponen konsep diri adalah gambaran diri, ideal diri, harga diri, peran diri dan identitas diri (Stuart, 2007). Faktor-faktor yang mempengaruhi konsep diri adalah pola asuh orang tua, lingkungan sosial budaya, fisik, psikologis, dukungan keluarga, penyakit dan spritual (Potter, 2005). 
Pasien pasca stroke yang memandang dirinya secara negatif tidak mampu memandang sisi positif dari cacat yang dideritanya. Seseorang yang memiliki konsep diri negatif memandang dirinya tidak berguna lagi, putus asa, tidak berdaya, gagal, merasa ditolak, menarik diri, menghindar untuk berinteraksi, murung, dan kehilangan semangat. Seseorang dengan konsep diri yang negatif mengalami tingkat pesimistik yang tinggi, dan akan mempengaruhi seluruh kehidupannya (Kozier, 2010). Banyak penderitanya yang menjadi cacat menjadi invalid tidak mampu mencari nafkah seperti sediakala menjadi tergantung pada orang lain dan tidak jarang menjadi beban keluarganya. Beban ini dapat berupa beban tenaga, beban perasaan, dan beban ekonomi (Lumbantobing, 2010).

Dukungan keluarga bagi pasien stroke sangat diperlukan selama pasien masih mampu memahami makna dukungan sosial tersebut sebagai penyokong kehidupannya. Dukungan keluarga memegang peranan penting dalam menentukan proses penyembuhan seseorang termasuk pada pasien stroke. Adanya dukungan keluarga dapat membantu penderita menghadapi masalahnya. Tidak efektifnya koping individu disertai kurangnya dukungan keluarga dapat memicu timbulnya perasaan yang bersifat depresi (ringan, sedang, berat) yang dapat berkembang menjadi gangguan konsep diri (Kuntjoro, 2012).

Hasil penelitian Kartini (2013) di Poliklinik Syaraf Rumah Sakit Daerah Provinsi Sulawesi Selatan ditemukan hasil $49,5 \%$ pasien stroke memiliki konsep diri negatif dan 33,3\% kurangnya dukungan keluarga. Hasil penelitian Septika (2014) RS PKU Muhammadiyah Surakarta ditemukan hasil ada hubungan dukungan keluarga dengan konsep diri pada pasien stroke ( $\mathrm{p}$ value $=0,021)$.

Berdasarkan data penderita stroke yang dirawat di RS. Stroke Nasional Bukittinggi terjadi peningkatan kunjungan pada tahun 2014 sebanyak 9880 pasien sedangkan di tahun 2015 sebanyak 10.752 jiwa. Data kunjungan poliklinik sebanyak 597 pasien pada bulan Desember 2015 (Profil RS. Stroke Nasional Bukittinggi, 2015).

Berdasarkan latar belakang tersebut peneliti tertarik meneliti "Apakah ada Hubungan dukungan keluarga dengan perubahan konsep diri pada pasien pasca stroke di Poliklinik Saraf Rumah Sakit Stroke Nasional Bukittinggi tahun 2016“.

\section{METODE PENELITIAN}

Jenis penelitian yang digunakan analitik untuk melihat kejadian yang diteliti dengan desain penelitian yang digunakan adalah cross sectional. Waktu penelitian dilaksanakan pada bulan Desember 2015 - Agustus 2016. Pengumpulan data pada tanggal 06 - 17 Juni 2016. Populasi dalam penelitian ini adalah seluruh pasien stroke haemoragik yang datang berkunjung di Poliklinik Saraf Rumah Sakit Stroke Nasional Bukittinggi sebanyak 46 orang.

\section{HASIL PENELITIAN}

\section{Karakteristik Responden}

Tabel 1 Karakteristik Responden di Poliklinik Syaraf RSSN Bukittinggi Tahun 2016

\begin{tabular}{|c|c|c|c|}
\hline No & Karakteristik & f & $\%$ \\
\hline \multirow[t]{3}{*}{1.} & \multicolumn{2}{|l|}{ Pendidikan } & \\
\hline & Rendah (SD dan SMP) & 18 & 39,1 \\
\hline & $\begin{array}{lll}\text { Tinggi } \quad \text { (SMA } & \text { dan } \\
\text { Perguruan Tinggi) } & \end{array}$ & 28 & 60,9 \\
\hline \multicolumn{2}{|c|}{ Jumlah } & 46 & 100 \\
\hline \multirow[t]{6}{*}{2.} & \multicolumn{3}{|l|}{ Usia } \\
\hline & $36-45$ tahun (Dewasa & 3 & 6,5 \\
\hline & Akhir) & 14 & 30,4 \\
\hline & 46 - 55 tahun (Lansia & 29 & 63,1 \\
\hline & Awal) & & \\
\hline & \multicolumn{3}{|l|}{$>55$ tahun (Lansia) } \\
\hline \multicolumn{2}{|c|}{ Jumlah } & 46 & 100 \\
\hline \multirow[t]{3}{*}{3.} & \multicolumn{3}{|l|}{ Pekerjaan } \\
\hline & Bekerja & 37 & 80,4 \\
\hline & Tidak Bekerja & 9 & 19,6 \\
\hline \multicolumn{2}{|c|}{ Jumlah } & 46 & 100 \\
\hline \multirow[t]{3}{*}{4.} & \multicolumn{3}{|c|}{ Lama Menderita } \\
\hline & $<5$ tahun & 20 & 43,4 \\
\hline & $\geq 5$ tahun & 26 & 56,6 \\
\hline \multicolumn{2}{|c|}{ Jumlah } & 46 & 100 \\
\hline
\end{tabular}

Berdasarkan hasil penelitian didapatkan karakteristik yang memiliki pendidikan SMA dan Perguruan Tinggi sebanyak 28 orang $(60,9 \%)$ dan usia $>55$ sebanyak 29 orang $(63,1 \%)$ sedangkan yang bekerja sebanyak 37 orang $(80,4 \%)$ dan lama menderita $\geq 5$ tahun sebanyak $(56,6 \%)$.

\section{Konsep Diri}

Tabel 2 Konsep Diri Pasien Pasca Stroke di Poliklinik Syaraf RSSN Bukittinggi 


\section{Tahun 2016}

Pada tabel 2 dapat dilihat bahwa dari 46 responden, sebanyak 20 orang $(43,5 \%)$ memiliki

\begin{tabular}{llcc}
\hline No. & Konsep Diri & $\boldsymbol{f}$ & $\boldsymbol{\%}$ \\
\hline 1. & Negatif & 20 & 43,5 \\
\hline 2. & Positif & 26 & 56,5 \\
\hline & Jumlah & $\mathbf{4 6}$ & $\mathbf{1 0 0}$
\end{tabular}

konsep diri negatif.

\section{Dukungan Keluarga}

Tabel 3. Dukungan Keluarga

Pasien Pasca Stroke di Poliklinik Syaraf RSSN Bukittinggi

\begin{tabular}{llcc}
\hline No. & Dukungan Keluarga & $\boldsymbol{f}$ & $\boldsymbol{\%}$ \\
\hline 1. & Tidak Mendukung & 19 & 41,3 \\
\hline 2. & Mendukung & 27 & 58,7 \\
\hline & Jumlah & $\mathbf{4 6}$ & $\mathbf{1 0 0}$
\end{tabular}

Pada tabel 3 dapat dilihat bahwa dari 46 responden, sebanyak 19 orang $(41,3 \%)$ memiliki keluarga tidak mendukung.

\section{Analisis Bivariat}

Tabel 4. Hubungan Dukungan Keluarga Dengan Konsep Diri Pasien Pasca Stroke

\begin{tabular}{|c|c|c|c|c|c|c|c|}
\hline \multirow{3}{*}{$\begin{array}{l}\text { Dukungan } \\
\text { Keluarga }\end{array}$} & \multicolumn{4}{|c|}{ Konsep Diri } & \multirow{2}{*}{\multicolumn{2}{|c|}{ Jumlah }} & \multirow{3}{*}{$P$ value } \\
\hline & \multicolumn{2}{|c|}{ Negatif } & \multicolumn{2}{|c|}{ Positif } & & & \\
\hline & $\mathrm{f}$ & $\%$ & $\mathrm{f}$ & $\%$ & $\mathrm{f}$ & $\%$ & \\
\hline $\begin{array}{l}\text { Tidak } \\
\text { Mendukung }\end{array}$ & 13 & 68,4 & 6 & 31,6 & 19 & 100 & \\
\hline Mendukung & 7 & 25,9 & 20 & 74,1 & 27 & 100 & 0,010 \\
\hline Jumlah & 20 & 43,5 & 26 & 56,5 & 46 & 100 & \\
\hline
\end{tabular}

Pada tabel 4 dapat dilihat bahwa dari 19 responden yang memiliki dukungan keluarga yang tidak mendukung lebih tinggi pada konsep diri negatif sebanyak 13 orang $(68,4 \%)$. Berdasarkan uji statistik didapatkan $p=0,010$ dimana $\mathrm{p}$ value $<0,05$. Ada hubungan bermakna antara dukungan keluarga dengan konsep diri pasien pasca stroke di Poliklinik Syaraf RSSN Bukittinggi Tahun 2016

\section{PEMBAHASAN}

Setelah dilakukan analisis data, selanjutnya akan dilakukan pembahasan terhadap variabel, adapun pembahasan dari analisis tersebut dapat dilihat sebagai berikut:

\section{Konsep Diri}

Hasil penelitian menunjukkan bahwa dari 46 responden, sebanyak 20 orang $(43,5 \%)$ memiliki konsep diri negatif. Hal ini dapat dilihat dari pengisian kuesioner yang menjawab tidak setuju $45,7 \%$ saya merasa memiliki kelebihan dari orang lain, 41,3\% tidak setuju walaupun saya dengan stroke tetap yakin dapat berkarya jika bersungguhsungguh, $41,3 \%$ tidak setuju merasa bisa menerima diri saya dengan penyakit yang saya alami.

Hasil penelitian ini hampir sama dengan penelitian yang dilakukan Kartini (2013) tentang hubungan dukungan keluarga dengan perubahan konsep diri pada pasien pasca stroke di Poliklinik Syaraf Rumah Sakit Khusus Daerah Provinsi Sulawesi Selatan ditemukan hasil $49,5 \%$ pasien stroke memiliki konsep diri negatif.

Konsep diri merupakan semua pikiran, keyakinan dan kepercayaan yang merupakan pengetahuan individu tentang dirinya mempengaruhi hubungannya dengan orang lain. Komponen konsep diri adalah gambaran diri, ideal diri, harga diri, peran diri dan identitas diri (Stuart, 2007).

Konsep diri adalah konsetualisasi individu terhadap dirinya sendiri. Ini merupakan perasaan subjektif individu dan kombinasi yang kompleks dari pemikiran yang disadari / tidak sadari, sikap dan persepsi. Konsep diri secara langsung mempengaruhi harga diri dan perasaan seseorang tentang dirinya sendiri. Meskipun dua istilah ini sering digunakan secara bersamaan, tetapi perawat harus membedakan keduanya agar dapat mengkaji klien dengan benar dan lengkap, serta membangun rencana perawatan berdasarkan kebutuhan klien (Potter, 2009).

Asumsi peneliti kurang dari separuh $(43,5 \%)$ pasien pasca stroke yang mengalami konsep diri negatif bisa disebabkan karena beberapa faktor, salah satunya adalah perubahan fisik. Dimana pasien pasca stroke 
mengalami perubahan bentuk fisiknya yang sudah berbeda, pasien memiliki mulut yang pelo, tangan bengkok dan keadaan kepala miring yang membuat pasien merasa tidak percaya diri bila berada didekat orang lain. Pasien mengalami gambaran diri yang negatif terhadap bentuk fisiknya. Selain itu dapat juga dilihat dari identitas diri responden dimana $41,3 \%$ tidak setuju merasa bisa menerima diri saya dengan penyakit yang saya alami. Seseorang yang mempunyai perasaan identitas diri yang kuat akan memandang dirinya berbeda dengan orang lain.

Kemandirian timbul dari perasaan berharga (aspek diri sendiri), kemampuan dan penyesuaian diri. Seseorang yang mandiri dapat mengatur dan menerima dirinya. Identitas diri terus berkembang sejak masa kanak-kanak bersamaan dengan perkembangan konsep diri. Hal yang penting dalam identitas adalah jenis kelamin.

Identitas jenis kelamin berkembang sejak lahir secara bertahap dimulai dengan konsep laki-laki dan wanita banyak dipengaruhi oleh pandangan dan perlakuan masyarakat terhadap masing-masing jenis kelamin tersebut.

Selain itu konsep diri yang negatif juga dikarenakan masih ada responden yang memiliki pendidikan rendah $(39,1 \%)$, dimana pendidikan yang rendah pada umumnya mempunyai wawasan yang sempit sehingga pasien merasa ada kekurangan dari orang lain. Selain pendidikan usia juga mempengaruhi psikologi pada pasien stroke, pada penelitian ini ditemukan usia > 55 tahun sebanyak $63,1 \%$. Usia yang sudah tua biasanya mengalami sensitif terhadap suatu hal sehingga pada pasien stroke yang sudah tua sering merasa ada kekurangan terhadap penyakitnya.

\section{Dukungan Keluarga}

Hasil penelitian menunjukkan bahwa dari 46 responden, sebanyak 19 orang $(41,3 \%)$ memiliki keluarga tidak mendukung. Hal ini dapat dilihat dari pengisian kuesioner yang menjawab 45,7\% keluarga jarang menasehati jangan banyak berfikir yang bukan-bukan, $45,7 \%$ keluarga jarang menghibur saya jika sedih dengan stroke yang dialaminya, 47,8\% keluarga jarang memberikan pujian dan perhatian pada saya dengan stroke yang dialaminya, $45,7 \%$ keluarga jarang memberikan support pada saya untuk bergaul pada lingkungan, $45,7 \%$ keluarga jarang membantu saya mengganti pakaian, 45,7\% keluarga selalu tidak mendampingi saya ketika kontrol ulang ke rumah sakit.

Hasil penelitian ini hampir sama dengan penelitian yang dilakukan Kartini (2013) tentang hubungan dukungan keluarga dengan perubahan konsep diri pada pasien pasca stroke di Poliklinik Syaraf Rumah Sakit Khusus Daerah Provinsi Sulawesi Selatan ditemukan hasil 33,3\% keluarga tidak mendukung pasien stroke memiliki konsep diri negatif.

Asumsi peneliti kurangnya dukungan keluarga pada penelitian ini dapat dikarenakan kesibukan dalam bekerja, sehingga keluarga tidak dapat memperhatikan pasien dengan optimal. Selain itu keluarga juga menerima keadaan dari pasien stroke dan menerima kenyataannya sehingga keluarga kurang mendukung untuk mengantarkan ke tenaga kesehatan, keluarga jarang memberikan support dan keluarga karang memberikan pujian pada pasien.

Kurangnya perhatian keluarga terhadap pasien stroke ini dapat dikarenakan keluarga sibuk dengan kegiatannya masing-masing. Sehingga keluarga kurang memperhatikan tentang kebutuhan pasien seperti menghibur, menasehati dan memberikan pujian pada pasien.

\section{Hubungan Dukungan Keluarga Dengan Konsep Diri Pada Pasien Pasca Stroke}

Hasil penelitian menunjukkan bahwa bahwa dari 19 responden yang memiliki dukungan keluarga yang tidak mendukung lebih tinggi pada konsep diri negatif sebanyak 13 orang $(68,4 \%)$. Berdasarkan uji statistik didapatkan $\mathrm{p}=0,010$ dimana $\mathrm{p}$ value $<0,05$. Ada hubungan bermakna antara dukungan keluarga dengan konsep diri pasien pasca stroke di Poliklinik Syaraf RSSN Bukittinggi Tahun 2016

Tugas keluarga terhadap pasien pasca stroke dapat dilihat pada teori Mubarak (2010) memberi perawatan pada anggota keluarga sering kali keluarga telah mengambil tindakan yang tepat, tetapi jika keluarga masih merasa 
mengalami keterbatasan, maka anggota keluarga yang mengalami gangguan kesehatan perlu memperoleh tindakan lanjutan atau perawatan agar masalah yang lebih parah tidak terjadi. Perawatan dapat dilakukan di institusi pelayanan kesehatan atau dirumah apabila keluarga telah memiliki kemampuan melakukan tindakan untuk pertolongan pertama.

Hasil penelitian ini hampir sama dengan penelitian yang dilakukan oleh penelitian Septika (2014) hubungan dukungan keluarga dengan konsep diri pada RS PKU Muhammadiyah Surakarta ditemukan hasil ada hubungan dukungan keluarga dengan konsep diri pada pasien stroke $(\mathrm{p}$ value $=$ $0,021)$.

Menurut Setiadi (2008) dukungan keluarga dibagi menjadi empat kategori yaitu dukungan emosional yang melibatkan emosi, perhatian pada orang lain, penghargaan yang merupakan dukungan yang muncul melalui ekspresi penghargaan positif, instrumental yang dapat diberikan berupa bantuan langsung dan informasional yang dapat diberikan berupa nasehat, pengarahan dan saran.

Dukungan emosional merupakan dukungan yang melibatkan ekspresi cinta, emosi, percaya dan perhatian kepada orang lain. Dukungan penghargaan merupakan dukungan yang muncul melalui ekspresi penghargaan positif terhadap orang lain. Dukungan instrumental diberikan berupa bantuan langsung seperti membantu mengerjakan tugas-tugas yang ditimpa kesulitan dan dukungan informasional diberikan berupa nasehat, pengarahan saran, umpan balik mengenai bagaima seseorang bertindak (Setiadi, 2008).

Asumsi peneliti dapat disimpulkan bahwa lebih banyak keluarga yang tidak mendukung pada konsep diri negatif. Hal ini dikarenakan keluarga masih banyak yang beranggapan bahwa penderitaan pasien pasca stroke dapat teratasi meskipun tanpa adanya dukungan dari orang yang berarti atau keluarga.

Dukungan orang yang berarti atau keluarga merupakan penilaian terhadap dukungan yang diberikan oleh keluarga, orang lain dan lingkungan masyarakat terhadap pasien pasca stroke.
Dukungan keluarga dan masyarakat yang kurang akan membuat pasien mengalami perubahan negatif terhadap kehidupannya dan sebaliknya bila dukungan keluarga dan masyarakat cukup baik maka akan membuat pasien pasca stroke mengalami perubahan yang positif dalam kehidupannya. Kurangnya kepedulian keluarga, masyarakat, lingkungan atau teman sebaya akan berpengaruh terhadap konsep diri pasien pasca stroke.

\section{KESIMPULAN}

Kurang dari separuh $(43,5 \%)$ responden memiliki konsep diri negatif. Kurang dari separuh $(41,3 \%)$ responden memiliki keluarga tidak mendukung. Ada hubungan dukungan keluarga dengan konsep diri di Poliklinik Saraf Rumah Sakit Stroke Nasional Bukittinggi tahun 2016

\section{DAFTAR PUSTAKA}

Bustan, 2007. Epidemologi Penyakit Tidak Menular, Jakarta : Rineka Cipta.

Dalami, 2009. Asuhan Keperawatan Jiwa dengan Masalah Psikologis, Jakarta TIM

Dewanto, 2014. Stroke Gangguan Peredaran Darah Dalam Otak, Jakarta : EGC

Fransisca, 2008. Asuhan Keperawatan Pada Klien dengan Gangguan Sistem Persyarafan, Jakarta : Salemba Medika.

Hidayat, 2010. Metode Penelitian Keperawatan dan Teknik Analisis Data, Jakarta : Salemba Media.

Hamilton, 2010. Keperawatan Jiwa. Edisi Revisi. PT Refika Aditama : Bandung.

Hariyanto, 2010. Teori Hirarki Kebutuhan Maslow, http://www.belajar.psikologi.com, diakses tanggal 11 April 2016

Jahja, 2013. Psikologi Perkembangan, Jakarta: EGC

Junaidi, 2011. Stroke Waspadai Ancamannya, Yogyakarta : CV. Andi Offset

Kuntjoro, 2012, Pengantar Ilmu Antropologi, Jakarta: Rineka Cipta

Kozier, 2010, Fundamental of Nursing, Concept Process and Practice, Addison, Wesley Publishing Company Inc, California.

Kartini, 2013. Hubungan Dukungan Keluarga Dengan Perubahan Konsep Diri Pada 
Pasien Pasca Stroke di Poliklinik Syaraf Rumah Sakit Khusus Daerah Provinsi Sulawesi Selatan

Keliat, 2008. Proses Keperawatan Kesehatan Jiwa. Jakarta : EGC

Kemenkes, RI, 2013. Gangguan Jiwa. Jakarta

Lumbantobing, 2010. Stroke : Bencana

Pendarahan di Otak, Jakarta : Balai Penerbit FKUI

Maglaya, 2009. Perawatan Kesehatan Keluarga ; Suatu Proses, Pusdiknakes Depkes RI, Jakarta.

Mubarak, 2010. Ilmu Keperawatan Komunitas Konsep dan Aplikasi, Jakarta : Salemba Medika

Notoatmodjo, 2012. Metodologi Penelitian Kesehatan. Jakarta : Rineka Cipta

Potter, Perry, 2005. Fundamental Keperawatan. Edisi 4. Jakarta. EGC

Pudiastuti, 2011. Penyakit Pemicu Stroke, Yogyakarta : Nuha Medika

Purba, 2009. Mekanisme Kerja Akupuntur dan Aplikasi Klinis, Jakarta

Profil Rumah Sakit Stroke Nasional Bukittinggi, 2014

Rasyid, 2011. Unit Stroke : Manajemen Stroke Secara Komprehensif. Balai Penerbit : FKUI, Jakarta.
Riskesdas, 2013. Cakupan Angka Gangguan Jiwa di Indonesia. Jakarta

Septika, 2014. Hubungan Dukungan Keluarga dengan Konsep Diri pada RS PKU Muhammadiyah Surakarta.

Syaiful, 2009. Patogenesis dan Diagnosis Stroke, Surabaya : Unair

Salbiah , 2010. Konsep Holistik Dalam Keperawatan Melalui Pendekatan Model Adaptasi Sister Callista Roy

Setyowati, 2008, Asuhan Keperawatan Keluarga Konsep dan Aplikasi Kasus, Edisi Revisi, Mitra Cendikia, Yogyakarta

Sobur, 2013. Psikologi Kesehatan, Jakarta : EGC

Smeltzer, Bare. 2001. Buku Ajar Keperawatan Bedah Brunner dan Suddarth. Volume 2, Jakarta: EGC.

Sunaryo. 2004. Psikologi Untuk Keperawatan. Jakarta : EGC.

Setiadi, 2008. Konsep \& Proses Keperawatan Keluarga, Yogyakarta : Graha Ilmu.

Stuart, 2007. Buku Saku Jiwa, Jakarta : EGC

Suliswati, 2012 Konsep Dasar Keperawatan Kesehatan Jiwa, Jakarta : EGC

Wartonah. 2011. Kebutuhan dasar manusia \& Proses keperawatan. Jakarta. Salemba Medika 